\title{
PELESTARIAN SITUS MAKAM SUNAN GIRI SECARA BERKELANJUTAN
}

\author{
A. Tutut Subadyo* \\ Jurusan Arsitektur Universitas Merdeka Malang \\ *tutut.subadyo@unmer.ac.id
}

\begin{abstract}
ABSTRAK
Pengelolaan Situs Makam Sunan Giri yang kurang memperhatikan tata kelola dan belum proporsional akan mendegradasi nilai serta maknanya sebagai peninggalan sejarah. Hal tersebut tercermin dari hadirnya bangunan baru yang tidak memiliki nilai kesejarahan namun tampil cukup menonjol seperti tiang-tiang lampu di pelataran parkir, gapura bentar baru, kios cinderamata, dan museum memunculkan permasalahan dalam upaya pelestarian situs makam tersebut. Sekait dengan fenomena tersebut maka dilakukanlah pengkajian untuk memformulasikan konsep pelestarian situs Makam Sunan Giri. Kajian untuk penyusunan formulasi konsep dan operasionalisasi pelestarian Makam Sunan Giri ini menggunakan pendekatan spatial arsitektural dan historis arkeologis. Konsep pelestarian didekati melalui pemugaran dan revitalisasi sebagai upaya agar kelestarian dan keutuhan artefak arsitektur pada situs tersebut terlaksana serta berkelanjutan. Dengan demikian situs Makam Sunan Giri ini nantinya tetap terjaga peran dan fungsinya sebagai monument, fakta, dan data sejarah yang bernilai tinggi. Upaya pelestarian situs Makam Sunan Giri ini ditujukan untuk merangsang gairah kebudayaan, menjadi sumber inspirasi, daya cipta dan tumpuan kesadaran, dalam mengembangkan kepribadian bangsa.
\end{abstract}

Kata kunci-giri, makam, pelestarian, situs, sunan

\section{PENDAHULUAN}

Situs Makam Sunan Giri merupakan salah satu warisan sejarah penyebaran agama Islam di Indonesia yang telah menjadi objek wisata religi. Sejauh ini, karakter yang nampak dari situs ini lebih dipandang sebagai komplek makam. Namun senyatanya elemen yang ada di dalamnya bukan hanya makam tetapi juga bangunanbangunan arsitektur. Letaknya pada perbukitan Giri, di Kecamatan Kebomas, Kabupaten Gresik, Jawa Timur dibangun berdasarkan konsep kosmologis yang mengedepankan kesejajaran atau keseimbangan antara makrokosmos dan mikrokosmos (Tjandrasasmita, 1963; Untoro, H, 1981). Penempatannya di lahan perbukitan yang tinggi diduga karena masih dipengaruhi oleh unsur-unsur kebudayaan Indonesia
Hindu. Demikian halnya dengan bangunan-bangunan arsitektur yang terdapat di dalam komplek makam tersebut ditinjau dari keletakan, arsitektur maupun pola hiasnya masih merupakan kelanjutan tradisi bangunan pra Islam.

Keberadaan situs Makam Sunan Giri ini selain karena kesakralan untuk kegiatan ritual umat Islam diperkirakan juga erat kaitannya dengan faktor kekuasaan. Di dalam komplek situs ini terdapat makam-makam keluarga Sunan Giri yaitu: Sunan Dalem, Sunan Tengah, Sunan Kulon, Nyai Ageng Selo dan ahli waris yang lain (Untoro, H, 1981). Kondisi situs secara makro merupakan kawasan bukit kapur yang dikelilingi perkampungan penduduk. Bagian belakang situs merupakan lokasi pabrik, sehingga udara 
di sekitarnya sering terpapar polutan dan cemaran udara. Situs Makam Sunan Giri ini kebersihan lingkungannya juga perlu mendapat perhatian, karena pengunjung - peziarah tingkat kesadaran lingkungannya belum memadai, dimana mereka seringkali makan-minum di dalam kawasan makam dan membuang sampah sembarangan.

Selain itu interpretasi yang terbangun tentang artefak warisan sejarah Wali Songo ini relatif masih belum memadai sehingga menjadi kendala dalam memahami sejarah, makna, dan fungsinya. Oleh karena itu, penelaahan ini dilakukan untuk menggali pemahaman karakteristiknya dan dapat dikembangkan fungsinya. Hasil penelaahan ini selanjutnya ditindaklanjuti untuk menyusun langkahlangkah pelestarian. Tujuan dari penulisan ini adalah untuk mendesiminasikan hasil penelaahan berupa strategi pengelolaan dan pelestarian situs Makam

\section{Sunan Giri.}

\section{METODE}

Kajian untuk penyusunan konsep dan operasionalisasi pelestarian makam sunan giri ini menggunakan pendekatan spatial arsitektural dan historis arkeologis. Analisis spatial ditekankan pada aspek lingkungan makro sekitar kawasan situs dan tapak dari situs tersebut, sedangkan analias arsitekturalnya dilakukan melalui aspek keruangan pada situsnya yang terdiri dari parameter tata ruang luar dan tata bangunannya. Analisis arsitektural secara kualitatif diinterpretasikan melalui bentukan masing-masing tipologi bangunan pada situs, utamanya bangunan pada area sakral khususnya bangunan cungkup makam Sunan Giri dan keluarganya. Analisis historis arkeologis dilakukan dengan melakukan penilaian terhadap aspek historis, aspek fungsi, dan aspek estetikanya, yang diakumulasikan dalam nilai integritasnya.

Dengan dua pendekatan tersebut selanjutnya dirumuskan konsep pelestariannya baik yang bertumpu pada kegiatan pemugaran maupun revitalisasinya.

\section{PEMBAHASAN}

\section{Kawasan Makam}

Eksistensi situs Makam Sunan Giri ini ditelaah berdasarkan analisis historis arkeologis dan spatial arsitektural untuk menyusun formulasi konsep pelestariannya. Kegiatan ini merupakan penugasan dari Direktorat Permuseuman, Direktorat Jenderal Kebudayaan Kementerian Pendidikan dan Kebudayaan, tahun 2013, untuk menyusun konsep perencanaan revitalisasi situs Makam Sunan Giri (Subadyo, 2013).

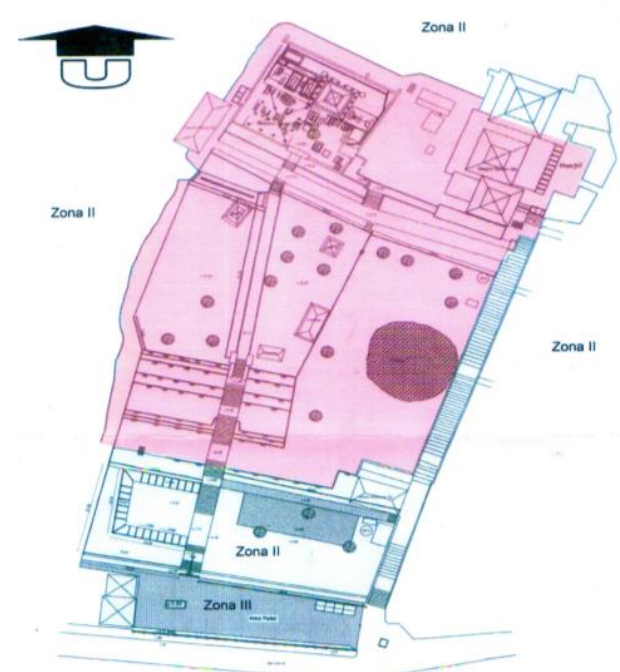

Gambar 1. Site Plan Situs makam Sunan Giri 
Sebagaimana diketahui bahwa secara umum tatanan filosofis dan fungsi situs Makam Sunan Giri dapat dibagi menjadi tiga bagian, yaitu area profan, area transisi, dan area sakral. Tatanan ini dibagi lagi dalam kelompok-kelompok berdasarkan fungsi bangunan menurut letak dan elemennya. Berdasarkan fungsi bangunannya, situs ini terbagi menjadi lima kelompok, yaitu : 1) pelataran parkir, 2) gapura -gapura, 3) makam-makam para santri murid Sunan Giri, 4) makam Sunan Giri beserta anak dan isteri dan pendopo, dan 5) masjid Jami’. museum). Kemudian ruang transisi (makam-makam para santri dan keluarganya). Pada area paling belakang (makam Sunan Giri dan masjid) merupakan ruang sakral, dengan nilai kesucian paling tinggi ((Lembaga Research Pesantren Luhur Islam Jawa Timur,1974; Subadyo, 2013). Sedangkan secara vertikal ruang profan terletak pada elevasi terendah pada teras pertama. Ruang selanjutnya yaitu area transisi, setingkat lebih tinggi dari ruang profan, yaitu pada teras kedua dan teras ketiga. Area yang terakhir atau ruang yang tingkatannya paling tinggi merupakan ruang sakral. Area ini terletak paling belakang di sebelah utara dan

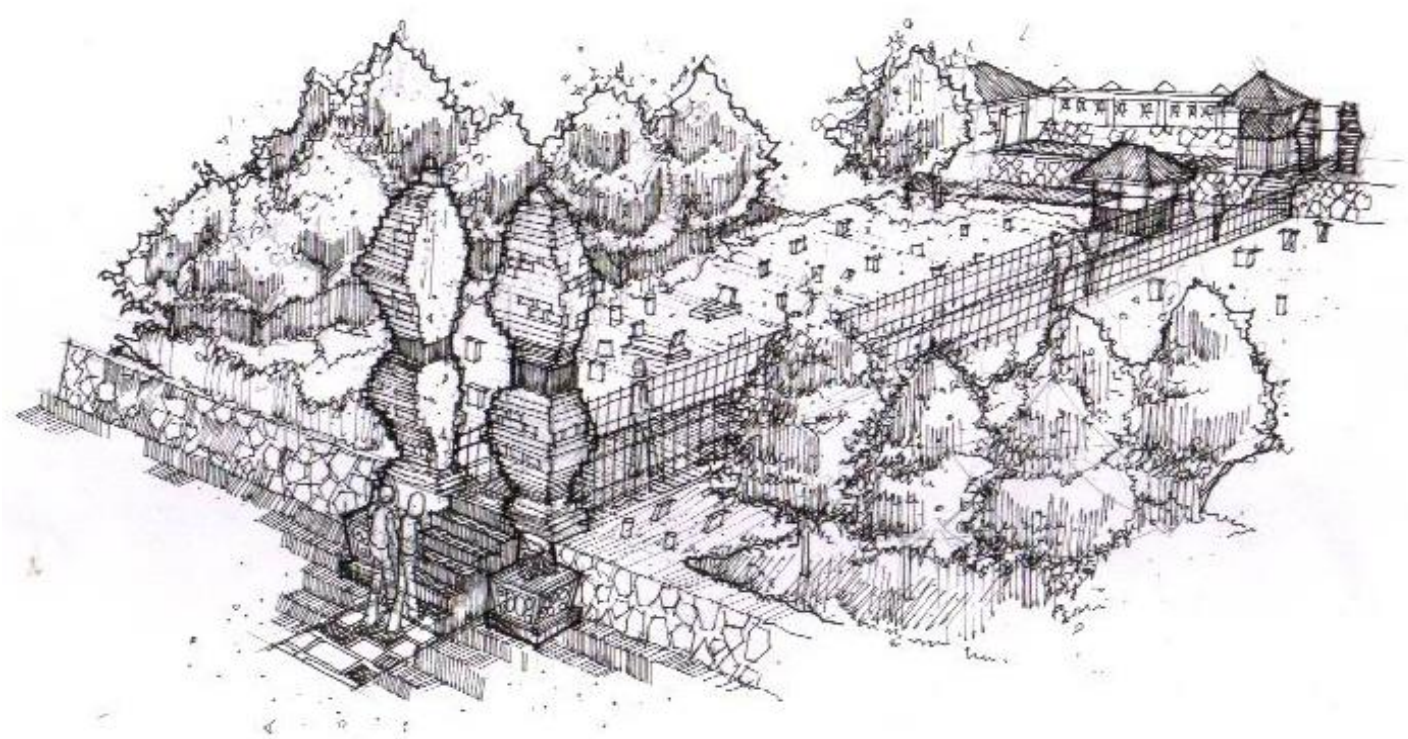

Gambar. 2. Sekuen Kawasan Situs Makam Sunan Giri

Konsep tatanan situs secara horizontal tersusun dari depan ke belakang. Ruang profan ada pada area paling depan (pelataran parkir, kios cinderamata, dan pada tapak yang memiliki elevasi paling tinggi.

Area sakral tersebut dibagi menjadi dua ruang, yaitu ruang bersemayannya makam Sunan Giri beserta keluarga dan area Masjid Jami'. Area makam Sunan Giri dan makam isteri, anak, serta sahabat merupakan 
ruang paling sakral/suci. Di tempat ini peziarah melakukan doa dan dzikir. Pada ruang ini selain terdapat bangunan cungkup makam Sunan Giri, juga terdapat cungkup makam isteri dan cungkup makam anak-anaknya, serta bangunan pendopo. Area lainnya pada ruang sakral tersebut adalah bangunan Masjid Jami'.
Berdasarkan analisis dan pengkajian yang dilakukan di komplek Situs Makam Sunan Giri ditemukenali adanya beberapa bangunan yang telah mengalami kerusakan sedang dan berat, Sekait dengan itu perlu segera dilakukan pelestarian dengan melakukan pemugaran dan revitalisasi.

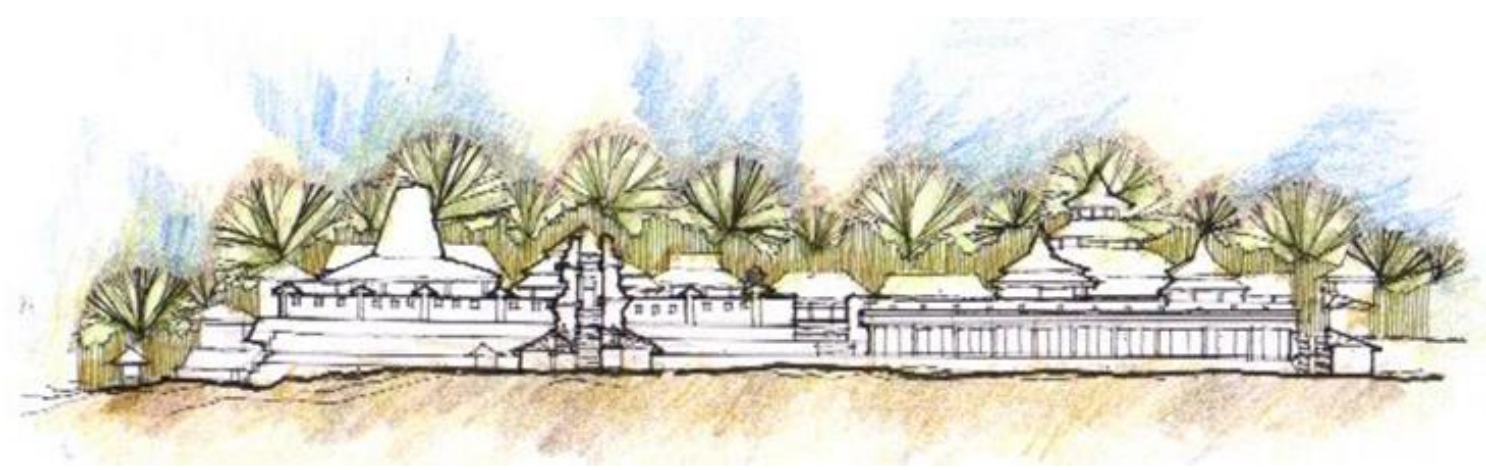

Gambar 3. Penampang Membujur Kawasan Makam Sunan Giri

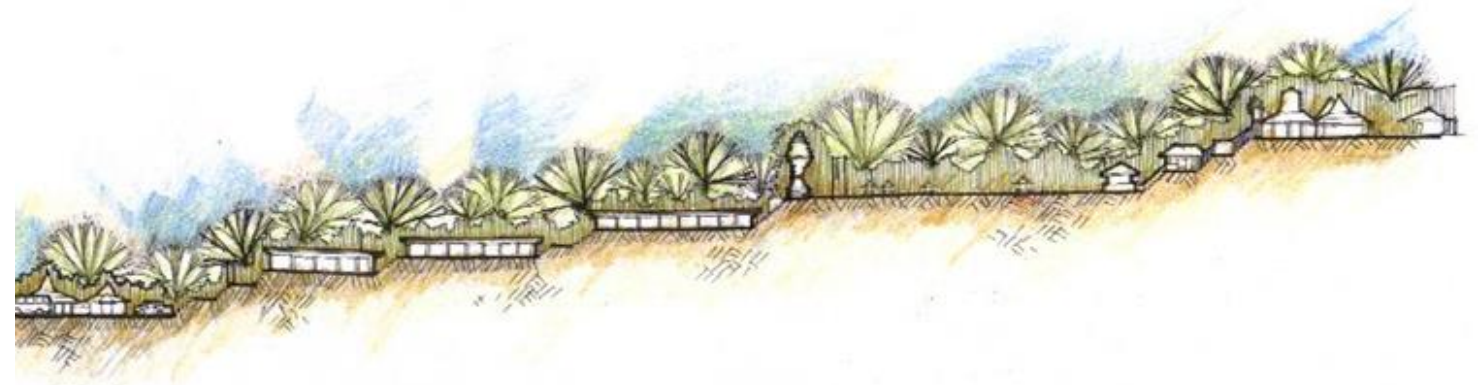

Gambar 4. Penampang Melintang Kawasan Makam Sunan Gir 


\section{Pemugaran}

Pemugaran situs Makam Sunan Giri dimaksudkan untuk melestarikan keutuhan situs, dan sumber sejarah. Untuk mempertahankan keasliannya, diperlukan ketelitian dan pengetahuan teknis arkeologis dan arsitektural. Berdasarkan kajian dan amatan lapang, beberapa artefak dan bangunan yang perlu dipugar adalah: (1) Pipi tangga Gapura berhiaskan pelipit empat persegi dan pelipit mahkota bentuk sulur-suluran yang mengalami keretakan atau kerenggangan pada bagian natnya, (2) Gapura Naga berbentuk bentar dengan hiasan pelipit mahkota, pelipit empat persegi, dan pelipit bergerigi pada bagian kaki, badan, dan puncak, yang keadaannya telah rusak, retak serta miring, dan badan gapura keseluruhannya telah aus serta arcanya telah patah dan pipi tangganya rusak, (3) Gapura Paduraksa yang mengalami kerusakan pada bagian antara gapura dan pilar, (4) Bangunan Cungkup Makam Sunan Giri yang terletak di atas batur batu kapur berbentuk bujur sangkar dihias dengan ukiran timbul, badan cungkup, atap sirap, dan balok sunduknya banyak yang rusak/rapuh, serta sebagian makam di halaman mengalami kemelesakan, kemiringan dan batu nisannya aus. Makam Sunan Giri sendiri berada di dalam bilik 'krobongan' berukuran 210 x $40 \mathrm{~cm}$. Pada bagian atas kijingnya ditancapkan nisan dari batuan andesit berbentuk pipih membujur arah utara selatan. (5) Cungkup Makam Sunan Prapen yang sebagian besar sudah rapuh dan rusak, (6) Cungkup Makam Panembahan Kawisguwo, dinding yang mengelilinginya rusak dan retak, juga konstruksi dalamnya sudah rapuh, serta beberapa jirat makam melesak, dan (7) Cungkup Makam Panembahan Agung, yang sudah miring, konstruksi kayunya lapuk, dan makam dalam kondisi miring/melesak.

Untuk melaksanakan pemugaran, diperlukan langkahlangkah yang efektif, ekonomis dan efisien. Dalam pelaksanaan pekerjaan pemugaran, alat dan bahan bangunan memegang peranan sangat penting disamping teknik dan tenaga pelaksananya.

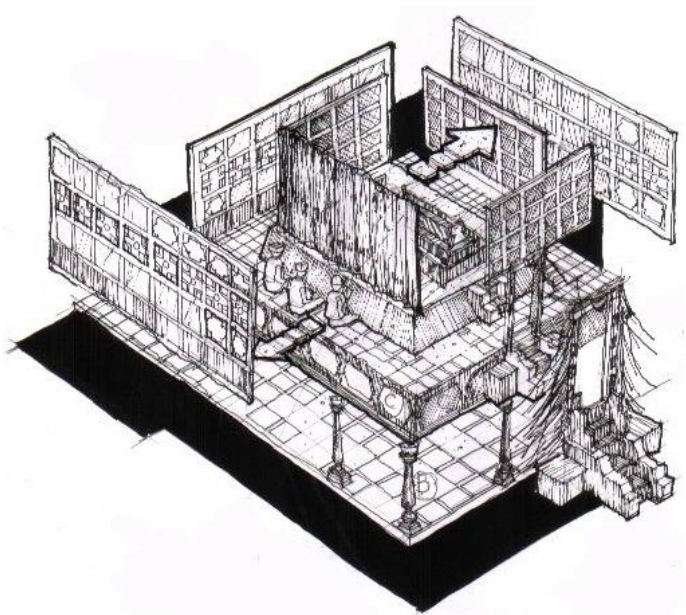

Gamba 5. Kerobongan tempat disemayamkannya Makam Sunan Giri yang diusulkan untuk dipugar.

Teknik pemugaran situs Makam Sunan Giri, meliputi:

1) Penyelidikan keteknikan dan arkeologis arsitektural. Kegiatan ini dilaksanakan, untuk mendapatkan data selengkap dan seakurat mungkin.

2) Pengukuran dan penggambaran artefak dan bangunan bersejarah yang akan dipugar untuk kepentingan dokumentasi dan rekonstruksi serta sebagai pedoman pemugaran.

3) Pengadaan sarana kerja berupa bangunan untuk tempat penyimpanan bahan dan alat, serta pembersihan halaman sebagai daerah kerja.

Selanjutnya dilakukan pemugaran artefak dan bangunan bersejarah dalam komplek situs Makam Sunan Giri meliputi. 
1) Pemugaran Gapura:

Bangunan gapura dari batu kapur (mergel), teknis pemugarannya, antara lain dilakukan dengan:

- Pembongkaran: sebelum batu-batu dibongkar, diberi tanda dulu bagian permukaan atasnya mempergunakan cat utamanya pada hubungan batu yang satu dengan lainnya. Pemberian tanda penghubung ini, dibeda-bedakan pada setiap sambungan untuk mempermudah dalam merekonstruksi kembali, juga mempermudah pencarian batu yang hilang.

- Penyusunan percobaan: batu-batu hasil pembongkaran ditampung dan disusun secara terbalik, bagian atas diletakkan pada lapis bawah dan sebaliknya, hal ini untuk mempermudah pemasangan kembali.

- Pemasangan kembali: Setelah hasil dari percobaan sudah baik dan benar, langkah selanjutnya adalah memasang kembali pada tempat asalnya. Dalam pemasangan kembali ini diusahakan nat-nat susunan batu tetap rapat, dan permukaan batu sisi luar (lapisan kulit) tetap lurus dan rata, barulah dicor dengan air semen pada nat-nat batunya. Untuk mencegah air semen mengalir keluar, bagian nat sebelah luar ditutup dengan tanah liat. Demikian seterusnya pemasangan dilaksanakan selapis demi selapis sampai pada bagian puncak. Untuk memperkokoh susunan batu luarnya (kulit) diberi ankur besi tahan karat pada bagian dalamnya dan pemasangannya dihubungkan dengan lapisan batu sebelah dalam (batu isian), selanjutnya lubang tempat ankur tersebut, ditutup dengan perekat campuran.

2. Pemugaran bangunan Cungkup Makam Sunan Giri, secara garis besarnya, meliputi: (a) pemasangan pondasi dan tembok bangunan cungkup; (b) penggantian lantai ubin; (c) perbaikan tiang-tiang penyangga konstruksi atap; (d) perbaikan plafon/pyan; dan $€$ perbaikan atap bangunan cungkup

3. Penataan kembali batu-batu jirat (makam), yang ada di komplek situs Makam Sunan Giri.

4. Penyelesaian terakhir dari kegiatan pemugaran, adalah : (a) pemberian tanda pada batu dan kayu baru. (b) redrawing hasil pemugaran; (c) pembuatan bangunan gudang (storage); dan (d) pembersihan halaman.

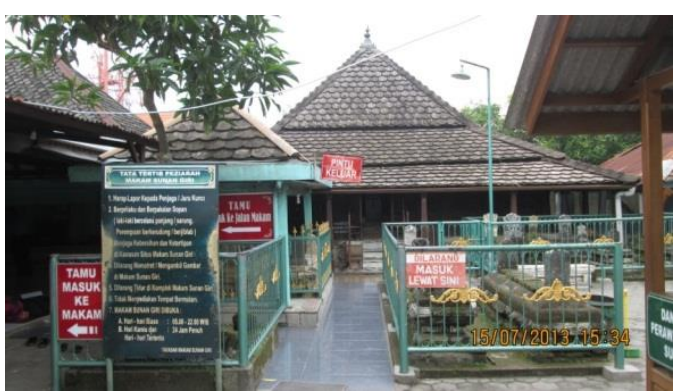

Gambar 6. Bangunan Cungkup Makam Sunan Giri yang perlu pemugaran

\section{Revitalisasi}

Revitalisasi difokuskan pada zona halaman utama Makam Sunan Giri (bagian teratas dari situs), dengan melakukan merencanakan pernaungan terhadap artefak dan bangunan yang ada di dalamnya. Pertimbangan utamanya adalah sebagai upaya untuk melindungi bangunan dari kerusakan yang semakin parah. Kriteria yang digunakan untuk merevitalisasi adalah hasil analisis nilai integritas berdasarkan : 1) nilai sejarah (kronologis/usia, jumlah fakta kesejarahan, jumlah keunikan, tingkat terjadinya event sejarah, dan tingkat 
keutuhan artefak), 2) nilai estetika (representasi gaya dan citra, proporsi, ritme, kontinyuitas, dan skala), dan 3) nilai fungsi (kenyamanan, aksesibilitas dan keterpautan kawasan, jumlah fasilitas, dan aktivitas serta manfaat sosial). Dari hasil penilaian tersebut maka proteksi terhadap artefak bangunan bersejarah yang ada merupakan keniscayaan yang tidak bisa ditunda.

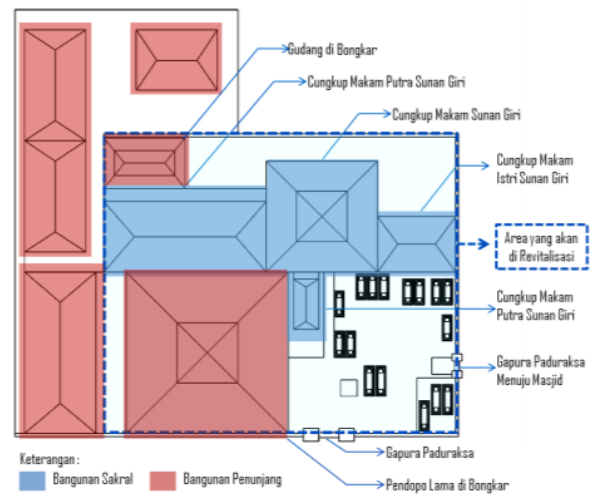

Gambar 7. Rencana perletakan Pendopo baru pada zona Makam Sunan Giri yang diusulkan untuk direvitalisasi

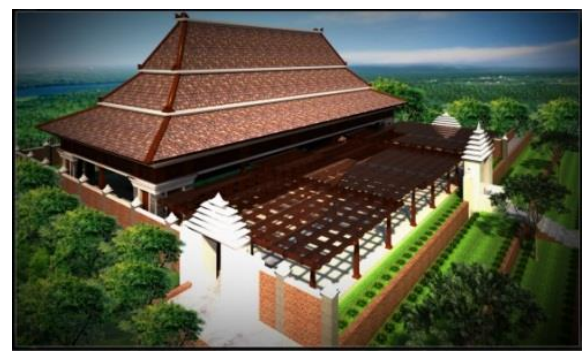

Gambar 8. Design bangunan Pendopo Agung baru sebagai bangunan pernaungan cungkup Makam Sunan Giri

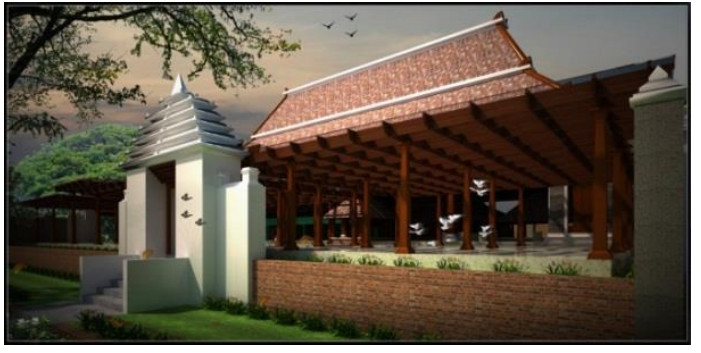

Gambar 9. Pendopo Agung baru sebagai penaung cungkup Makam Sunan Giri dan keluarganya agar terjaga dari kerusakan yang lebih parah.

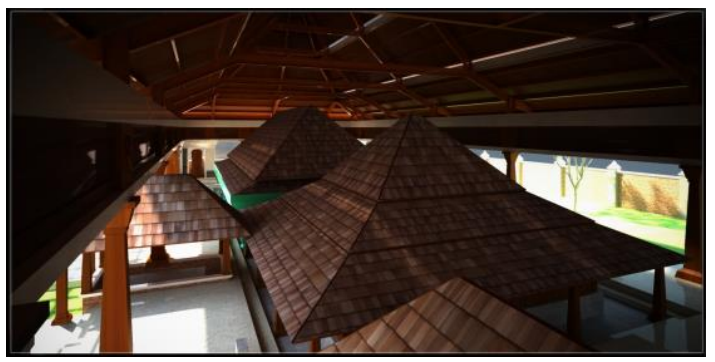

Gambar 10. Interior bangunan Pendopo Agung.

\section{Kesimpulan}

Berdasarkan hasil penelahan disimpulkan strategi pelestarian situs Makam Sunan Giri sebagai berikut: (1) perlu dilakukan pengembangan dan perbaikan potensi sumber daya situs, (2) pengembangan aktivitas serta fasilitas situs, berpedoman pada konsep pengembangan kawasan secara berlanjutan, (3) penataan lahan di dalam situs terintegrasi dan kompatibel dengan bentang alam bukit kapur, (4) perbaikan sistem pengelolaan situs Makam Sunan Giri, (5) pengembangan kerjasama pengelolaan situs secara 
sinergis antara BPCP Trowulan, Pemerintah Kabupaten Gresik dan pengelola makam (Yayasan Sunan Giri), (6) peninjauan sistem pengelolaan situs Makam Sunan Giri, dan (7) meningkatkan perlindungan kawasan situs Makam Sunan Giri dari tindakan vandalism.

\section{Daftar Pustaka}

Anonim. (1997). Laporan Studi Lapangan Arkeologi Islam di Situs Sunan Giri. Jurusan Sejarah Kebudayaan Islam. Fakultas Adab IAIN Sunan Ampel, Surabaya.

Drajat, Hari Untoro (1981). Kepurbakalaan Giri, Jakarta, Fakultas Sastra Indonesia, Universitas Indonesia Jakarta.

Hasyim, Umar (1979). Sunan Giri, Menara, Kudus.

Hoop, A.N.J. Thaa Th van der. Indonesische Siermotizen, 1949. Ragam-Ragam Perbiasan Indonesia, Depdikbud, Jakarta.

Kasdi, A. (1990). Transkrip Babad Gresik versi Pegan. IKIP Surabaya.

Kasdi, A (1997). Babad Gresik, telaah Historiografis dalam Studi Sejarah. University Press IKIP Surabaya.

Lembaga Research Pesantren Luhur Islam Jawa Timur (1974). Sejarah dan Dakwah Islamiyah Sunan Giri, P3SG Gresik.

Soekmono,. R, (1959). Pengantar Sejarah Kebudayaan Indonesia, djilid III, Djakarta.

Solichin Salam, (1960). Sekitar Wali Sanga, Menara, Kudus.

Solichin Salam, (1964). Sedjarah Islam Di Djawa, Djakarta.

Subadyo, AT (2013). Laporan Akhir Perencanaan Revitalisasi Situs Makam Sunan Giri di Gresik, Direktorat Permuseuman, Direktorat Jenderal Kebudayaan, Kementerian Pendidikan dan Kebudayaan, Jakarta.
Sukadi, M (1995). Makam-makam Wali Sanga di Jawa. Depdikbud, Jakarta.

Sumintardja, Djauhari, 1978. Kompedium Sejarah Arsitektur, Jilid I, Yayasan Lembaga Pendidikan Masalah Bangunan, Bandung.

Tan Khun Swie. (1926). Serat Suluh Walisanga. Jilid I, II. Kediri.

Tjandrasasmita, Uka, (1963). “Riwayat Penyelidikan Kepurbakalaan Islam Di Indonesia”, dimuat di dalam 50 Tahun Lembaga Purbakala dan Peninggalan Nasional, 1913 - 1963. Jakarta. 